\title{
Treatment of Zenker's diverticulum using a novel grasping-type scissors forceps allows fast, safe, and effective endoscopic diverticulotomy $\square$
}

(๑) $\Theta \odot$

\author{
Authors \\ Timo Rath, Jürgen Siebler, Markus F. Neurath, Andreas Nägel
}

Institution

Department of Medicine 1, Division of Gastroenterology, Ludwig Demling Endoscopy Center of Excellence, University Hospital Erlangen, Erlangen, Germany

submitted 18.9.2017

accepted after revision 13.3 .2018

\section{Bibliography}

DOI https://doi.org/10.1055/a-0603-3357 |

Endoscopy International Open 2018; 06: E659-E663

(c) Georg Thieme Verlag KG Stuttgart · New York

ISSN 2364-3722

\section{Corresponding author}

Timo Rath, MD, Ludwig Demling Endoscopy Center of Excellence, Department of Medicine 1, Division of Gastroenterology, University Hospital Erlangen, Ulmenweg 18, 91054 Erlangen, Germany

Fax: +49-9131-8535209

Timo.Rath@uk-erlangen.de

\section{ABSTRACT}

Background and study aims Although several endoscopic techniques have been described for Zenker's diverticulotomy, no standardized endoscopic approach has been established in clinical routine to date. This study aimed to assess the efficacy and safety of endoscopic diverticulotomy using the Clutch Cutter.

Patients and methods Cricopharyngeal myotomy was performed in six prospectively enrolled patients with symptomatic Zenker's diverticulum, using the Clutch Cutter. Procedural details such as duration, complications, and technical success were recorded and compared to the outcomes of 15 patients who received needle-knife-based myotomy.

Results Myotomy with the Clutch Cutter was feasible in all six patients with complete diverticulotomy in a single session in all patients. Mean procedure time of the Clutch Cutter myotomy was 19 minutes without major complications. During follow-up, one patient had diverticulum recurrence after 10 months, which was successfully re-treated. Mean procedure time with the needle-knife was 43 minutes and a mean of 2.7 myotomy sessions was required for complete diverticulotomy.

Conclusion Endoscopic diverticulotomy using the Clutch Cutter is safe, effective, and fast. Larger studies comparing myotomy using the Clutch Cutter with other endoscopic techniques are highly warranted.

\section{Introduction}

Zenker's diverticulum (ZD) is an acquired pulsing diverticulum with an outpouching of the mucosa and submucosa through Killian's triangle dorsally at the pharyngoesophageal junction. Impaired opening of the upper esophageal sphincter, increased hypopharyngeal bolus pressure, and reduced wall compliance [1 - 3] are etiologically involved in the development of ZD and, based on the pathophysiology of disease, myotomy of the cricopharyngeal muscle is the method of choice in symptomatic patients.

Techniques for the endoluminal therapy of ZD are mainly based on dissection of the cricopharyngeal muscle with argon plasma coagulation [4,5], monopolar coagulation using forceps, or knife-based incisions (needle-knife, Hook-knife) [2,611]. However, no standardized endoscopic approach has been established in clinical routine to date.

Originally developed for endoscopic submucosal dissection, the Clutch Cutter (CC; FUJIFILM Corporation, Tokyo, Japan) is a forceps-type resection device that can simultaneously grasp and cut or coagulate tissue with electrosurgical current that is concentrated at the closed blade to avoid unintentional incision $[12,13]$.

After a previous case report had shown successful cricopharyngeal myotomy with the CC [14], the aim of our study was to validate these findings in a larger cohort and to compare the 

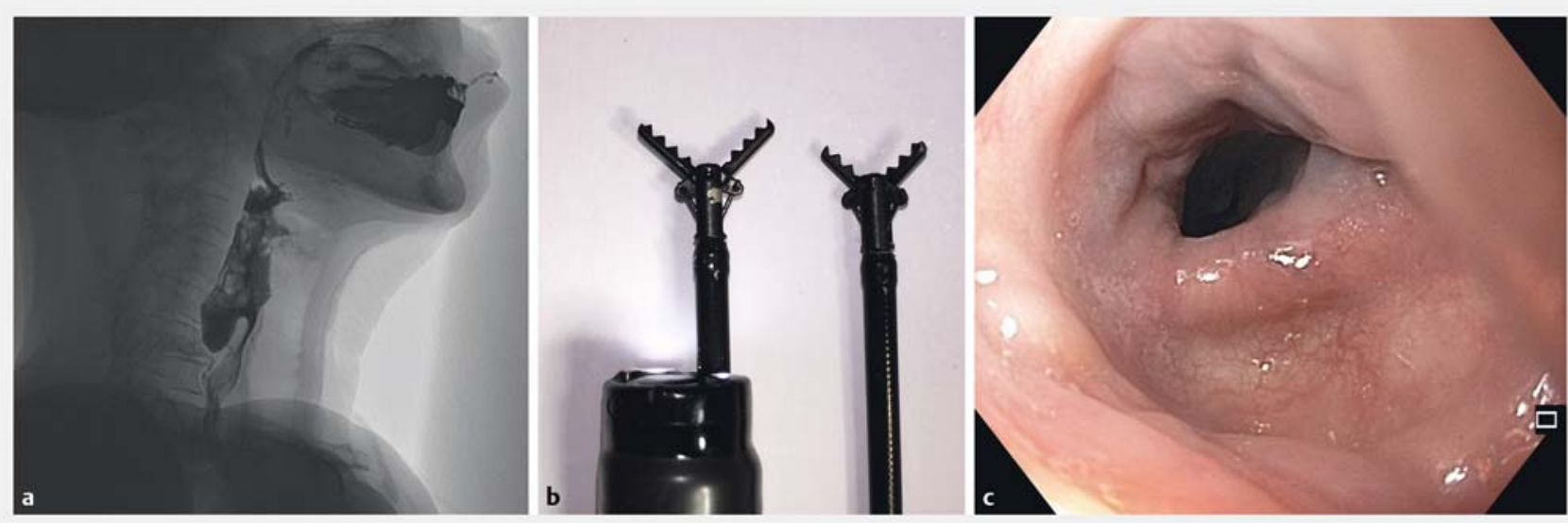

- Fig. 1 Zenker's diverticulotomy with the Clutch Cutter. a All patients had a Zenker's diverticulum Grade 4 on the Brombart scale as assessed by barium swallow. $\mathbf{b}$ The Clutch Cutter has a rotatable serrated jaw and is available in two sizes ( $3.5 \mathrm{~mm}$ and $5 \mathrm{~mm}$ jaw length). To concentrate electrosurgical current energy at the closed blade, the outer side of the CC is insulated. c Endoscopic view 12 months after the CC myotomy.

outcome of diverticulotomy with the CC against a needle-knifebased approach.

\section{Patients and methods}

\section{Patients and outcome measurement}

From 2015 to 2017, six patients (three female, three male) with symptomatic ZD were treated with diverticulotomy using the CC. Written informed consent was obtained from all patients. Before endoscopic diverticulotomy, barium swallow enema was performed to assess size and radiologic classification [15]. The study was approved by our institutional review board. The procedure time (time from first insertion to final withdrawal of the endoscope), amelioration of symptoms, and complications were assessed using a database prospectively formatted from the medical records.

Patients were followed up for a mean of 12 months. During follow-up, one patient died from non-Hodgkin lymphoma 4 weeks after myotomy. Results of the CC myotomy were compared to retrospectively analyzed outcomes of a total of $15 \mathrm{pa}-$ tients (nine male, six female) who received near complete diverticulotomy with needle-knife myotomy.

\section{Myotomy of the cricopharyngeal muscle with the Clutch Cutter}

The CC is a rotatable forceps-type resection device that can simultaneously grasp and cut or coagulate tissue with electrosurgical current. The CC is rotatable to the desired orientation and has a $0.4-\mathrm{mm}$-wide and 3.5 -or 5-mm-long serrated cutting edge to facilitate grasping ( $\triangleright$ Fig. 1b). Furthermore, the outer side of the forceps is insulated, therefore electrosurgical current energy is concentrated at the closed blade to avoid unintentional incision.

All endoscopies were performed under propofol sedation. Diverticulotomy with the CC was performed using a standardized protocol. In brief, esophagus, duodenum, and the stomach were examined initially. After having withdrawn the endoscope, a conventional feeding tube was placed through the nose of the patient. The endoscope was then re-inserted with a 4-mm distal cap (MH-464; Olympus) on the tip and placed in front of the septum between the ZD and the esophageal lumen ( $\triangleright$ Fig. 2a). Tissue of the septum was then grasped with the opened CC ( $\triangleright$ Fig.2b). With tissue inside the forceps, the CC was gently pulled back to avoid cutting too deeply and electrocautery was applied using an Erbe Vio 200 D-system (Erbe, Tübingen, Germany) with the following settings: Forced coagulation 30 W, Endo Cut $Q$ with effect 1, duration 3, interval 1. The initial cut led to exposure of the cricopharyngeal muscle underneath the septum ( $\triangleright$ Fig. $2 \mathbf{c}$ ).

The procedure for selectively grasping muscle fibers ( $\triangleright$ Fig. 2d), gentle pull-back of the CC, and finally electrocautery of septum muscle fibers ( $\triangleright \mathbf{F i g} \mathbf{2} \mathbf{2 e}$ ) to dissect the muscle fibers was repeated until the septum had been cut a few millimeters above the bottom of the diverticulum, resulting in a near complete diverticulotomy ( $>$ Fig. 2f). Importantly, during the whole procedure, the CC allowed the selective grasping and cutting of the muscle fibers while avoiding cutting too deeply through gentle pull-back maneuvers with the closed CC. A complete procedure for cricopharyngeal myotomy with the CC is shown in $>$ Video 1.

\section{Results}

Clinical characteristics of the patients and outcomes of the CC myotomy are summarized in $>$ Table 1 . All patients had a ZD grade 4 on the Brombart scale ( $>$ Fig. 1a). Myotomy with the CC was feasible in all six patients with a technical success rate of $100 \%$. Near complete diverticulotomy was achieved in a single session in all patients ( $\triangleright$ Fig. 2 ). Mean procedure time for diverticulotomy with the CC was 19 minutes (range 10-30 minutes). There were no major complications such as obvious perforations, or severe bleeding requiring re-intervention. \ Fig.1c shows an endoscopic view 12 months after the CC myotomy. In one patient, minor bleeding occurred during myotomy which 

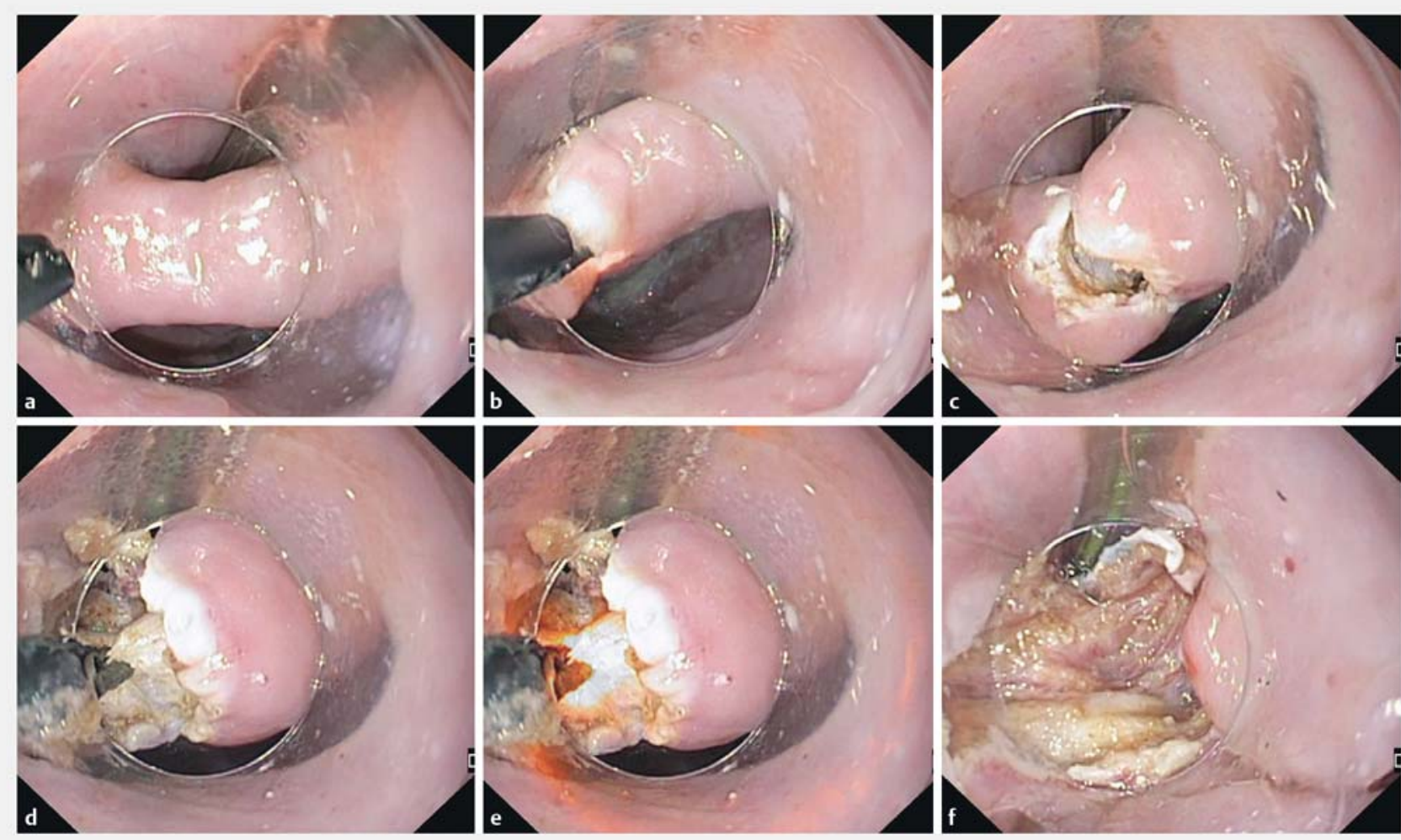

- Fig. 2 Different steps of cricopharyngeal myotomy with the Clutch Cutter. a In the first step, after placement of a nasogastric tube, the endoscope with a 4-mm distal cap is placed right above the septum between the Zenker's diverticulum and the esophageal lumen. $\mathbf{b}$ Tissue of the septum is then grasped with the opened CC and with tissue inside the closed forceps, the CC is gently pulled back to avoid cutting too deeply and electrocautery is applied during retraction. c The initial cut led to exposure of the cricopharyngeal muscle underneath the septum. d With the CC, muscle fibers of the cricopharyngeal muscle are grasped and gently pulled back. e During retraction, electrocautery is applied to achieve myotomy of the grasped muscle fibers. The procedure for selectively grasping muscle fibers, gentle pull-back of the CC, and finally dissection of septum muscle by electrocautery is repeated until the septum has been completely cut. $\mathbf{f}$ Final result of myotomy using the CC with a near complete diverticulotomy.

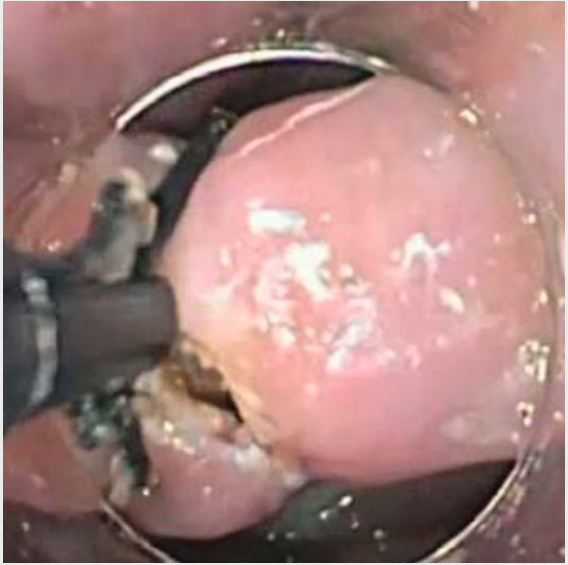

$\nabla$ Video 1 Complete procedure for cricopharyngeal myotomy with the Clutch Cutter. was stopped immediately during the procedure through coagulation with the closed CC. Mean hospital stay was 3 days (range 2-4 days). All patients had symptomatic relief after myotomy with the $\mathrm{CC}$, and a single patient experienced a diverticulum recurrence 10 months after the initial myotomy which was then successfully treated with a second diverticulotomy using the CC.

In comparison, mean procedure time during needle-knife myotomy was 43 minutes per session and to achieve near complete diverticulotomy, a mean of 2.7 myotomy sessions was required per patient. Bleeding occurred in seven patients undergoing needle-knife myotomy. While in six patients, bleeding was immediately recognized during the procedure and controlled through argon plasma coagulation, in one patient, delayed and severe bleeding occurred requiring a second emergency gastroscopy with argon plasma coagulation and subsequent hemoclip application. In three out of the 15 patients undergoing needle-knife myotomy, cervical emphysema developed shortly after the procedure and CT scan showed pneumomediastinum without any signs of gastrografin leakage in these patients. Under conservative management, cervical emphysema progressively declined in all three patients. In one patient, 
- Table 1 Patients' clinical characteristics and outcomes of Zenker's diverticulotomy with the CC.

\begin{tabular}{|c|c|c|c|c|c|c|c|c|c|c|c|}
\hline Patient & Sex & $\begin{array}{l}\text { Age, } \\
\text { years }\end{array}$ & $\begin{array}{l}\text { Zenker } \\
\text { size, } \\
\text { mm }\end{array}$ & $\begin{array}{l}\text { Grade on } \\
\text { Brombart } \\
\text { scale }\end{array}$ & Symptoms & $\begin{array}{l}\text { Procedure } \\
\text { time, min }\end{array}$ & $\begin{array}{l}\text { Hospital } \\
\text { stay, days }\end{array}$ & $\begin{array}{l}\text { Compli- } \\
\text { cations }\end{array}$ & $\begin{array}{l}\text { Follow- } \\
\text { up, } \\
\text { months }\end{array}$ & $\begin{array}{l}\text { Symp- } \\
\text { tom } \\
\text { relief }\end{array}$ & $\begin{array}{l}\text { Recur- } \\
\text { rence }\end{array}$ \\
\hline 1 & $\mathrm{~F}$ & 94 & $15 \times 15$ & 4 & $\begin{array}{l}\text { Dysphagia, } \\
\text { regurgitation }\end{array}$ & 10 & 3 & N & 9 & Y & $\mathrm{N}$ \\
\hline 2 & $M$ & 84 & $56 \times 33$ & 4 & $\begin{array}{l}\text { Aspiration, } \\
\text { dysphagia }\end{array}$ & 18 & 2 & $\begin{array}{l}\text { Minor } \\
\text { bleeding }{ }^{1}\end{array}$ & 3 & Y & $\mathrm{N}$ \\
\hline 3 & M & 65 & $42 \times 30$ & 4 & Dysphagia & 30 & 3 & $\mathrm{~N}$ & 10 & Y & N \\
\hline 4 & $\mathrm{~F}$ & 80 & $28 \times 23$ & 4 & $\begin{array}{l}\text { Dysphagia, } \\
\text { weight loss }\end{array}$ & 25 & 2 & N & 24 & Y & N \\
\hline 5 & $M$ & 74 & $30 \times 20$ & 4 & $\begin{array}{l}\text { Aspiration, } \\
\text { dysphagia }\end{array}$ & 15 & 4 & N & $1^{2}$ & Y & N \\
\hline 6 & $\mathrm{~F}$ & 71 & $50 \times 30$ & 4 & $\begin{array}{l}\text { Dysphagia, re- } \\
\text { fractory cough }\end{array}$ & 15 & 4 & N & 25 & Y & $Y^{3}$ \\
\hline \multicolumn{12}{|c|}{$\begin{array}{l}{ }^{1} \text { Minor bleeding was defined as bleeding that occurred and was successfully treated during CC myotomy. Major bleeding was defined as bleeding that occurred aft } \\
\text { CC myotomy and required a second emergency endoscopy. } \\
{ }^{2} \text { This patient died from non-Hodgkin lymphoma } 4 \text { weeks after CC myotomy. } \\
{ }^{3} \text { Recurrence occurred } 10 \text { months after the initial CC myotomy as a Zenker's diverticulum Brombart Grade } 3 \text { which was then successfully treated with a second } \\
\text { diverticulotomy using the CC. }\end{array}$} \\
\hline
\end{tabular}

a small mediastinal perforation occurred during needle-knife myotomy and was immediately closed via hemoclips. Under close monitoring, no signs of mediastinitis developed in this patient. Mean hospital stay was 7 days (range 3-10 days) for patients with needle-knife myotomy.

\section{Discussion}

As a common principle across all techniques used for endoscopic treatment of ZD, the septum between the diverticulum and esophagus within which the cricopharyngeal muscle is contained is dissected along its entire longitudinal content, resulting in a cricopharyngeal myotomy. During this procedure, identification of the depth of incision is the most critical aspect of endoscopic Zenker's treatment. If the incision is too short, this can result in incomplete cricopharyngeal myotomy, thereby predisposing for clinical recurrence, which has been reported in up to $25 \%$ of patients with endoluminal treatment of ZD [16]. On the other hand, cutting too deeply can result in mediastinal perforation. However, due to the absence of reliable anatomic landmarks defining the depth of incision during endoscopy, the inferior border is difficult to define endoscopically and with mediastinal perforation rates as high as $20 \%$ [11], this represents the most frequent and most serious complication of endoluminal ZD treatment. Unfortunately, with the techniques mentioned above, the direction of incision is inevitably directed from proximal to distal and in the absence of secure landmarks other than the muscular fibers, this harbors the risk of cutting too deeply with subsequent perforation.

This led some investigators to assess devices where the incision can be controlled from bottom to top. Repici and co-workers used an approach in which the hook knife is used to hook into the tissue and pull upwards before cutting, thus inverting the direction of the cut [8]. In that report, the technical success of the hook-knife-based myotomy was $91.7 \%$ and of the 32 patients treated, one patient developed cervical emphysema after the procedure which disappeared under conservative management [8]. In our study, we used the CC for cricopharyngeal myotomy. Because of its ability to grasp, thereby enabling accurate and selective targeting of muscle fibers, and to pull the target tissue in an upward direction away from the proper muscle layer along with coagulation concentrated at the closed blade, the CC allowed for very controlled and precise movements at the target site with a direction of incision from distal to proximal, as described by Repici et al. with the hook-knife [8].

This careful selection of the amount of tissue to be cut seems to be especially critical when approaching and dissecting the very distal part of the septum. With the CC, technical success was $100 \%$ and complete diverticulotomy was achieved in a single session in all patients with a mean duration of 19 minutes. No major complications such as perforation, or severe bleeding requiring re-intervention were observed during diverticulotomy with the CC.

In contrast, with needle-knife-based myotomy performed in 15 patients with ZD in our department, a mean of 2.7 treatment sessions was required for complete diverticulotomy and with a mean duration of 43 minutes per session, procedure time was considerably longer compared to the CC. At the same time, our data illustrate that needle-knife myotomy might be more prone to the development of complications such as bleeding and mediastinal emphysema or perforation, an observation which can most likely be attributed to the inability to cauterize with the same instrument and to precisely control the depth of incision when cutting downwards. 
As a major limitation of our study, the number of patients treated with the CC is relatively small, so that far reaching conclusions cannot be drawn. Because of the different patient numbers treated with needle-knife and CC, and the current study design in which patients underwent cricopharyngeal myotomy with either of these devices consecutively, learning curve effects might have biased the results in favor of the CC. Hence, a direct comparison of the outcomes and complications may not be feasible from the current study and clearly, systematic analyses by randomized trials are necessary to address these aspects. Furthermore, with a mean of 12 months, the follow-up time was relatively short. Therefore, long-term recurrence of ZD after CC diverticulotomy cannot be excluded. Nevertheless, from these first experiences, we believe that, in our series, the CC allowed a precise and deep incision with almost complete disappearance of the septum after a single treatment session. Future randomized studies comparing different endoscopic approaches for diverticulotomy are highly warranted to identify the most effective and safest technique for endoluminal therapy of ZD.

\section{Competing interests}

None

\section{References}

[1] Cook I], Gabb M, Panagopoulos V et al. Pharyngeal (Zenker's) diverticulum is a disorder of upper esophageal sphincter opening. Gastroenterology 1992; 103: 1229-1235

[2] Ferreira LE, Simmons DT, Baron TH. Zenker's diverticula: pathophysiology, clinical presentation, and flexible endoscopic management. Dis Esophagus 2008; 21: 1-8

[3] Pech O. Esophageal disease. Endoscopy 2013; 45: 729-733
[4] Rabenstein T, May A, Michel J et al. Argon plasma coagulation for flexible endoscopic Zenker's diverticulotomy. Endoscopy 2007; 39: $141-145$

[5] Wahab PJ, Mulder C], den Hartog G et al. Argon plasma coagulation in flexible gastrointestinal endoscopy: pilot experiences. Endoscopy 1997; 29: $176-181$

[6] Christiaens P, De Roock W, Van Olmen A et al. Treatment of Zenker's diverticulum through a flexible endoscope with a transparent oblique-end hood attached to the tip and a monopolar forceps. Endoscopy 2007; 39: 137 - 140

[7] Costamagna G, Iacopini F, Tringali A et al. Flexible endoscopic Zenker's diverticulotomy: cap-assisted technique vs. diverticuloscopeassisted technique. Endoscopy 2007; 39: 146-152

[8] Repici A, Pagano N, Romeo F et al. Endoscopic flexible treatment of Zenker's diverticulum: a modification of the needle-knife technique. Endoscopy 2010; 42: 532 - 535

[9] Rivory J, Almahayawi A, Roman S et al. Endoscopic Zenker diverticulotomy using the window technique: a technical trick to improve the field of view. Endoscopy 2016; 48: (Suppl. 01): E63-64

[10] Sakai P, Ishioka S, Maluf-Filho F et al. Endoscopic treatment of Zenker's diverticulum with an oblique-end hood attached to the endoscope. Gastrointest Endosc 2001; 54: 760 - 763

[11] Vogelsang A, Preiss C, Neuhaus H et al. Endotherapy of Zenker's diverticulum using the needle-knife technique: long-term follow-up. Endoscopy 2007; 39: 131 - 136

[12] Akahoshi K, Akahane H, Murata A et al. Endoscopic submucosal dissection using a novel grasping type scissors forceps. Endoscopy 2007; 39: $1103-1105$

[13] Akahoshi K, Honda K, Akahane $\mathrm{H}$ et al. Endoscopic submucosal dissection by using a grasping-type scissors forceps: a preliminary clinical study (with video). Gastrointest Endosc 2008; 67: 1128-1133

[14] Neumann H, Loffler S, Rieger S et al. Endoscopic therapy of Zenker's diverticulum using a novel endoscopic scissor - the Clutch Cutter device. Endoscopy 2015; 47: (Suppl. 01): E430 - 431

[15] Brombart M. [Zenker's pharyngo-esophageal diverticulum; pathogenic considerations on radiological studies on 26 cases (23 cases in initial stage)]. J Belge Radiol 1953; 36: 166-197

[16] Huberty V, El Bacha S, Blero D et al. Endoscopic treatment for Zenker's diverticulum: long-term results (with video). Gastrointest Endosc 2013; 77: $701-707$ 